\title{
Uso do solo e monitoramento dos recursos hídricos no córrego do Ipê, Ilha Solteira, SP
}

\author{
Gilmar O. Santos $^{1}$ \& Fernando B. T. Hernandez ${ }^{2}$
}

\begin{abstract}
RESUMO
O Brasil possui grande potencial hídrico porém com deficiência em termos de monitoramento qualitativo, quantitativo e conhecimento das influências do uso do solo. Assim, realizou-se trabalho com o propósito de apresentar o monitoramento qualitativo e quantitativo das águas para fins de irrigação e as influências ocasionadas pelo uso e ocupação do solo na microbacia do córrego do Ipê, município de llha Solteira, São Paulo. O monitoramento qualitativo foi realizado no período de 2006 a 2011 e o quantitativo de 2009 a 2011. Para se constatar as influências utilizou-se a análise de correlação de Pearson. Verificou-se que, em sua maior parte, a microbacia é composta pela cultura de cana-de-açúcar e o maior uso em conflito com as áreas de preservação permanente são as áreas ociosas e de pastagem. A microbacia se caracterizou com altas concentrações de ferro e coliformes originados das áreas de pastagens degradadas e uso irregular e ocupação urbana e rural. As reduzidas áreas de preservação permanente, a má conservação do solo e a expansão das áreas urbanas, implicam na deterioração da qualidade e disponibilidade hídrica, gerando impactos socioeconômico e ambiental para a região.
\end{abstract}

Palavras-chave: ocupação do solo, qualidade de água,correlação estatística

\section{Land use and monitoring of water resources of Ipê stream, Ilha Solteira, SP}

\begin{abstract}
Brazil has great potential of water resources, however, with deficiency in terms of qualitative and quantitative monitoring and knowledge of the influences of land use. So, this study had the purpose of presenting the qualitative and quantitative monitoring of water for irrigation and the influences caused by the use and occupation of land in the watershed of Ipê stream, in the municipality of Ilha Solteira, São Paulo. The qualitative monitoring was conducted from 2006 to 2011 and the quantitative monitoring from 2009 to 2011. In order to evaluate the influences, the Pearson correlation analysis was used. It was found that the watershed is mostly made up by the crop of sugar cane and the use in conflict with areas of permanent preservation are the fallow areas and pasture. The watershed is characterized with high concentrations of iron and coliforms, originating from degraded pastures and irregular use of urban and rural occupation. The small permanent preservation areas, bad soil conservation and expansion of urban areas imply in the deterioration of the quality and availability of water, generating socio-economic and environmental impact in the area.
\end{abstract}

Key words: land occupation, water quality, statistical correlation 


\section{INTRODUÇÃO}

Vivemos em um modelo de desenvolvimento econômico baseado na exploração dos recursos naturais, sendo um dos maiores objetivos do século a busca pelo equilíbrio ambiental (Young, 2001). Os ambientes aquáticos sempre foram e serão um dos recursos naturais mais explorados devido às suas diversas finalidades (Moraes \& Jordão, 2002; Oliveira et al., 2011).

A Microbacia do Córrego do Ipê possui localização estratégica para o incentivo da agricultura irrigada de vez que favorece o aumento de produção e facilita seu escoamento.

Para Paz et al. (2000) a irrigação apresenta baixa eficiência média em nível mundial de apenas $37 \%$. Mesmo com oito meses de deficiência hídrica no solo (Hernandez et al., 2003; Santos et al., 2010) a região noroeste paulista se caracteriza como uma área tipicamente agrícola, o que evidencia a necessidade de avaliação da qualidade, a disponibilidade hídrica e a utilização de sistemas de irrigação para assegurar a produtividade das culturas possibilitando, inclusive, colheitas fora de época.

Esses aspectos evidenciam ser imprescindível o monitoramento quantitativo e qualitativo dos recursos hídricos como ferramenta de auxílio na identificação de possíveis impactos ambientais e as influências do entorno no meio aquático, a fim de propor prioridades e orientá-las em decisões futuras.

A disponibilidade dos recursos hídricos é apenas um fator a ser levado em consideração haja vista que o aspecto qualitativo começou a ganhar nova dimensão principalmente na produção agrícola de consumo in natura (Moura et al., 2011); assim, mananciais próximos às áreas urbanas merecem atenção especial em virtude da poluição difusa e de lançamentos de águas residuais de forma clandestina acarretando, sem dúvida, na sua degradação, prejudicando os múltiplos usos da água (Lima et al., 2004).

Em se tratando de qualidade de água para fins de irrigação, Ribeiro et al. (2005) descrevem que a combinação dos fatores físicos, químicos e biológicos é a principal causa de obstrução dos sistemas de irrigação. Dentre os parâmetros qualitativos mais comuns na região noroeste paulista, está o ferro total. Para Vanzela et al. (2010) o parâmetro possui alto poder de obstrução física dos tubos e emissores dos sistemas de irrigação localizada. Na ausência de oxigênio o ferro no solo se apresenta na forma solúvel $\left(\mathrm{Fe}^{2+}\right)$ e, quando em contato com o ar, passa para a forma insolúvel $\left(\mathrm{Fe}^{3+}\right)$ alterando a coloração da água e favorecendo a obstrução dos sistemas de irrigação. Barboza et al. (2011) destacam a atenção a esses elementos os quais poderiam comprometer a eficiência dos sistemas de irrigação, em especial o gotejamento e a microaspersão.

O monitoramento de microbacias hidrográficas ainda é pouco usual no Brasil, além de representar importância fundamental para o atual e o futuro abastecimento de água (Francisco \& Carvalho, 2004). De acordo com Brito et al. (2005) os recursos hídricos tendem a se tornar mais escassos devido aos processos de uso e poluição crescente, caso não haja ações energéticas visando às melhorias da gestão da oferta e da demanda de água.
Além dos impactos naturais, a Microbacia do Córrego do Ipê recebe influência direta da área urbana com perspectiva de expansão prevista no Plano Diretor Municipal, como área de interesse estratégico. Segundo Lima et al. (2004) e Poleto et al. (2010) mananciais próximos às áreas urbanas se tornam muito propícios à degradação ambiental acarretada pelo excesso de nutrientes e matéria orgânica carreado para os corpos hídricos, além da intensificação dos processos erosivos resultando, na maioria dos casos, em assoreamento, eutrofização e contaminação das águas reduzindo, assim, a disponibilidade e a qualidade do manancial.

Além do monitoramento, Nascimento et al. (2005) destacam o uso de geotecnologias como alternativa viável de se apurar com rigor as agressões ao meio ambiente e a importância das funções ambientais das áreas de preservação permanente (APP) as quais são justificadas por serem ambientes voltados à preservação da paisagem, fluxo gênico da fauna e da flora e por atuar como dissipador de energia erosiva das águas de chuva. Assim, a identificação de impactos agrícolas e ambientais deve ser caracterizada dentro do contexto das características e particularidade de uma região (Zalidis et al., 2002).

Este trabalho foi realizado com o propósito de se apresentar o monitoramento qualitativo e quantitativo das águas para fins de irrigação e as influências ocasionadas pelo uso e ocupação do solo na Microbacia do Córrego do Ipê, município de Ilha Solteira, noroeste do estado de São Paulo.

\section{MATERIAL E MÉTODOS}

Este trabalho foi conduzido na Microbacia do Córrego do Ipê, município de Ilha Solteira, região noroeste do Estado de São Paulo, localizado na folha de articulação $22 \mathrm{~K}$, entre as coordenadas geográficas $20^{\circ} 24^{\prime} 44,8^{\prime \prime} \mathrm{S}$ e $51^{\circ} 17^{\prime} 06,5^{\prime \prime} \mathrm{O}$ e $20^{\circ} 30^{\prime} 16,4^{\prime \prime} \mathrm{S}$ e $51^{\circ} 22^{\prime} 16,2^{\prime \prime} \mathrm{O}$ com altitude entre 290 a 370 $\mathrm{m}$ acima do nível do mar.

Dividiu-se a microbacia em quatro pontos estratégicos a fim de caracterizar a influência dos diversos usos e ocupação do solo, tal como, também, a contribuição do Córrego das Lagoas que compreende a área de estudo (Figura 1) em que a Tabela 1 apresenta a caracterização fisiográfica das quatro sub-bacias.

A Microbacia do Córrego do Ipê compreende $50,44 \mathrm{~km}^{2}$ (7,68\% da área do município) e faz parte da Unidade de
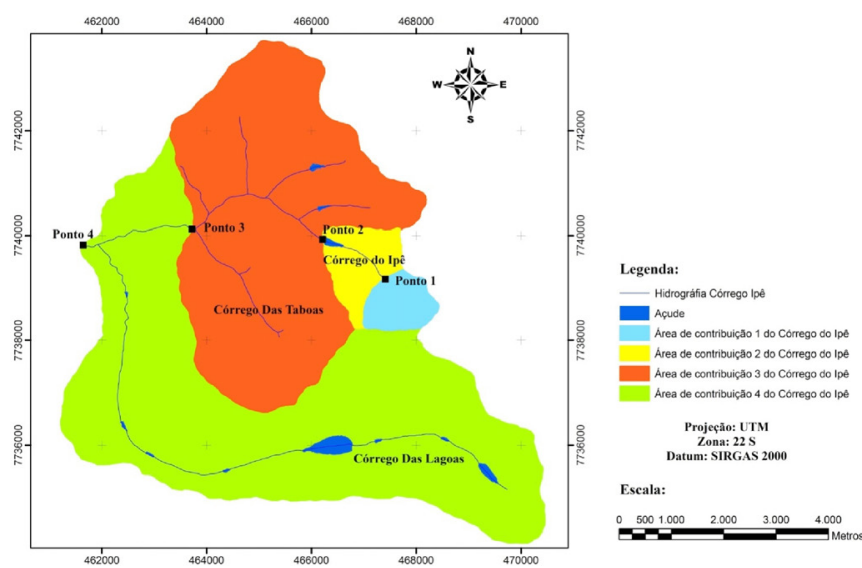

Figura 1. Microbacia do Córrego do Ipê com suas respectivas sub-bacias e pontos de monitoramento 
Tabela 1. Caracterização fisiográfica das Sub-Bacias do Córrego do Ipê

\begin{tabular}{|c|c|c|c|c|}
\hline \multirow{2}{*}{ Características } & \multicolumn{4}{|c|}{ Sub-Bacias } \\
\hline & 1 & 2 & 3 & 4 \\
\hline Área de drenagem $\left(\mathrm{km}^{2}\right)$ & 1,22 & 3,03 & 22,86 & 50,44 \\
\hline Perímetro $(\mathrm{km})$ & 4,23 & 7,33 & 21,25 & 33,44 \\
\hline Comprimento do leito principal $(\mathrm{km})$ & - & 1,59 & 4,50 & 6,6 \\
\hline Declividade equivalente $\left(\mathrm{m} \mathrm{m}^{-1}\right)$ & - & $6 \times 10^{-3}$ & $2 \times 10^{-3}$ & $1 \times 10^{-3}$ \\
\hline Fator de forma & 1,22 & 1,21 & 1,12 & 1,15 \\
\hline Coeficiente de compacidade & 1,08 & 1,18 & 1,24 & 1,32 \\
\hline Densidade de drenagem $\left(\mathrm{km} \mathrm{km}^{-2}\right)$ & - & 0,52 & 0,20 & 0,13 \\
\hline Ordem do córrego & $1^{0}$ & 10 & $3^{0}$ & $3^{0}$ \\
\hline Índice de circularidade & 0,85 & 0,71 & 0,64 & 0,57 \\
\hline Tempo de concentração (min) & - & 35,25 & 126,00 & 203,20 \\
\hline Vazão média plurianual $\left(\mathrm{m}^{3} \mathrm{~h}^{-1}\right) Q_{\text {esp }}$ & $3,6.10^{1}$ & $9,4.10^{1}$ & $7,2.10^{2}$ & $1,6.10^{3}$ \\
\hline Vazão de permanência com $95 \%$ de probabilidade $\left(\mathrm{m}^{3} \mathrm{~h}^{-1}\right) Q_{95 \%}$ & $1,2.10^{1}$ & $3,0.10^{1}$ & $2,2.10^{2}$ & $5,0.10^{2}$ \\
\hline Vazão mínima de 1 mês consecutivo com período de retorno de 10 anos $\left(\mathrm{m}^{3} \mathrm{~h}^{-1}\right) \mathrm{Q}_{1,10}$ & $1,1.10^{1}$ & $2,7.10^{1}$ & $2,1.10^{2}$ & $4,7.10^{2}$ \\
\hline Vazão mínima de 7 dias consecutivos com período de retorno de 10 anos $\left(\mathrm{m}^{3} \mathrm{~h}^{-1}\right) \mathrm{Q}_{7,10}$ & $0,8.10^{1}$ & $2,2.10^{1}$ & $1,6.10^{2}$ & $3,6.10^{2}$ \\
\hline
\end{tabular}

Gerenciamento de Recursos Hídricos do Rio São José dos Dourados (UGRHI-18). De acordo com a classificação climática de Köppen, Ilha Solteira apresenta clima subtropical úmido, Aw, com inverno seco e ameno e verão quente e chuvoso (Rolim et al., 2007) com temperatura média anual de $25,1{ }^{\circ} \mathrm{C}$ e precipitação média de 1.305,8 $\mathrm{mm}^{\text {ano }}{ }^{-1}$ (Área de Hidráulica e Irrigação UNESP Ilha Solteira).

Segundo Santos et al. (2010) a região noroeste paulista sofre deficiência hídrica durante oito meses chegando a $490 \mathrm{~mm}^{2} \mathrm{ano}^{-1}$ (abril a novembro) e com excedente hídrico de $179 \mathrm{~mm} \mathrm{ano}^{-1}$ (dezembro a março).

A região de Ilha Solteira faz parte da Província Geomorfológica do Planalto Ocidental, conhecido como região das "zonas indivisas", com característica de relevo colinoso representado pelas rochas sedimentares do Grupo Bauru (Lima et al., 2004). Os autores apresentam, ainda, as características do solo com predominância do Latossolo Vermelho (rico em sesquióxido), Argissolo Vermelho Eutrífico + Argissolo Vermelho - Amarelo e Neossolo Quartzarênico. A vegetação natural remanescente é composta de mata úmida e floresta latifoliada semidecídua ou mata-seca.

Os mapas foram determinados a partir da fusão de imagens de satélite disponibilizadas pelo Instituto Nacional de Pesquisas Espaciais (INPE) sendo imagem CBERS 2B, sensor HRC, órbita 160 , ponto 123 2, com resolução espacial de $2,7 \mathrm{~m}$ de 08 de setembro de 2008 e imagem Landsat-5, sensor TM, órbita 223 , ponto 74 , com resolução espacial de $30 \mathrm{~m}$ de 20 de junho de 2011. As representações cartográficas foram realizadas a partir do softwareArc Gis ${ }^{\circledR} 10$. A georreferência partiu da base de dados da NASA (Geocover). A segmentação foi realizada através da ferramenta de desenhos ketch tool a partir da função start editing do modo de edição vetorial, de forma manual, via tela do monitor. As classes de uso e a ocupação determinadas foram: açudes (AC), áreas ociosas em conflito (AOC), área de preservação permanente ociosa (APP ociosa), assentamento (ASS), cana-de-açúcar (CA), culturas perenes (CP), horticultura (HO), matas (MA), matas em áreas de preservação permanente (MAPP), pastagem (PA), residencial alta densidade (RAD), residencial baixa densidade (RBD), rodovias (RO) e várzeas (VA) além da rede hidrográfica, nascentes e limites de subbacias hidrográficas. A análise de conflitos com as áreas de preservação permanente foi realizada através da sobreposição de mapas temáticos.
O período de análises qualitativas compreendeu de abril de 2006 a setembro de 2011. Nos anos de 2006, 2009, 2010 e 2011 as coletas foram realizadas mensalmente; entretanto, no ano de 2007 foram bimensais e suspensas no ano de 2008. As análises físicas, químicas e biológicas realizadas, foram: temperatura (T), sólidos totais (ST), dissolvidos (SD) e suspensos (SS), turbidez (TU), pH, dureza total (DT), cálcio (CA), magnésio (MG), ferro total (FE), condutividade elétrica (CE), nitrito (NI), nitrato (NA), sulfato (SU) e coliformes fecais (CF) e totais (CT). Os parâmetros de análises de conformidade foram classificados de acordo os parâmetros estabelecidos por Nakayama \& Bucks (1986), Brasil (2005) e Ayers \& Westcot (1991). A Tabela 2 apresenta a metodologia utilizada nas análises de água.

Tabela 2. Síntese das metodologias, equipamentos e precisão nas análises de qualidade de água para fins de irrigação

\begin{tabular}{|c|c|c|c|}
\hline Parâmetro & $\begin{array}{l}\text { Unidade } \\
\text { de medida }\end{array}$ & Método & Precisão \\
\hline $\begin{array}{l}\text { Temperatura } \\
\text { Sólidos totais }\end{array}$ & ${ }^{\circ} \mathrm{C}$ & Termômetro & $0,5^{\circ} \mathrm{C}$ \\
\hline $\begin{array}{l}\text { Sólidos dissolvidos } \\
\text { Sólidos suspensos }\end{array}$ & $\mathrm{mg} \mathrm{L}^{-1}$ & Gravimétrico & $1,0 \mathrm{mg} \mathrm{L}^{-1}$ \\
\hline Turbidez & NTU & Nefelométrico & 0,01 NTU \\
\hline pH & - & Peagâmetro & 0,01 \\
\hline Condutividade elétrica & $\begin{array}{l}d S \mathrm{~cm}^{-1} \\
\text { a } 25^{\circ} \mathrm{C}\end{array}$ & Eletrodo de platina & $\begin{array}{l}1 \times 10^{-4} \mathrm{dS} \mathrm{cm}^{-1} \\
\text { a } 25^{\circ} \mathrm{C}\end{array}$ \\
\hline Ferro total & $\mathrm{mg} \mathrm{L}^{-1}$ & $\begin{array}{l}\text { Colorimétrico } \\
\text { ferro espectral }\end{array}$ & $0,1 \mathrm{mg} \mathrm{L}^{-1}$ \\
\hline Oxigênio dissolvido & $\mathrm{mg} \mathrm{L}^{-1}$ & $\begin{array}{l}\text { Winkler modificado } \\
\text { Titulação }\end{array}$ & $0,1 \mathrm{mg} \mathrm{L}^{-1}$ \\
\hline $\begin{array}{l}\text { Dureza total } \\
\text { Cálcio } \\
\text { Magnésio }\end{array}$ & $\mathrm{mg} \mathrm{L}^{-1}$ & Titulação & $1,0 \mathrm{mg} \mathrm{L}^{-1}$ \\
\hline Nitrito & $\mathrm{mg} \mathrm{L}^{-1}$ & Diazotação & $0,01 \mathrm{mg} \mathrm{L}^{-1}$ \\
\hline Nitrato & $\mathrm{mg} \mathrm{L}^{-1}$ & Redução de cádmio & $0,02 \mathrm{mg} \mathrm{L}^{-1}$ \\
\hline Sulfato & $\mathrm{mg} \mathrm{L}^{-1}$ & Sulfaver4 & $0,4 \mathrm{mg} \mathrm{L}^{-1}$ \\
\hline $\begin{array}{l}\text { Coliformes totais } \\
\text { Coliformes fecais }\end{array}$ & $\begin{array}{l}\text { NMP100mL-1 } \\
\text { de amostra }\end{array}$ & Contagem de bactérias & $\begin{array}{l}60 \mathrm{NMP}^{-1} \\
100 \mathrm{~mL}^{-1}\end{array}$ \\
\hline
\end{tabular}

As análises da disponibilidade hídrica tiveram início em março de 2009 até setembro de 2011. A medição da vazão foi determinada através da velocidade de fluxo da água realizada pelo molinete hidrométrico da marca Global Water, modelo FP101-FP201 e da área da seção transversal do córrego. 
A análise exploratória surgiu do erro padrão da média e dos valores máximos e mínimos e da correlação de Pearson, com análise de variância a nível de $5(*)$ e $1 \%(* *)$ de probabilidade, em que as variáveis dependentes foram atribuídas à qualidade dos recursos hídricos e as variáveis independentes ao uso e à ocupação do solo, segundo metodologia adotada por Vanzela et al. (2010). Os períodos chuvosos e secos foram determinados de acordo com Santos et al. (2010) baseados em excedente e deficiência hídrica.

\section{RESULTADOS E DISCUSSÃO}

A Tabela 3 apresenta a distribuição dos diferentes usos e a ocupação do solo correspondente a cada sub-bacia do Córrego do Ipê enquanto a Figura 2 se refere à respectiva espacialização da área.

Tabela 3. Uso e ocupação das Sub-Bacias do Córrego do Ipê, 2011

\begin{tabular}{lrrrr}
\hline \multirow{2}{*}{\multicolumn{1}{c}{ Uso e ocupação }} & \multicolumn{5}{c}{ Sub-Bacias } \\
\cline { 2 - 5 } & $\mathbf{1}$ & $\mathbf{2}$ & $\mathbf{3}$ & \multicolumn{1}{c}{$\mathbf{4}$} \\
\cline { 2 - 5 } Açude & 0,6 & 1,4 & 0,3 & 1,2 \\
Áreas ociosas em conflito & 0,6 & 0,4 & 2,8 & 2,1 \\
Assentamento & 0,0 & 8,8 & 16,9 & 7,7 \\
Cana-de-açúcar & 84,3 & 42,2 & 50,2 & 48,1 \\
Culturas perenes & 1,6 & 0,7 & 0,1 & 2,2 \\
Horticultura & 0,0 & 0,0 & 0,5 & 0,2 \\
Matas & 0,0 & 0,0 & 0,2 & 0,6 \\
Matas APP & 1,9 & 1,0 & 0,7 & 0,6 \\
Pastagens & 4,2 & 1,8 & 0,3 & 20,3 \\
Residencial alta densidade & 0,0 & 0,0 & 16,4 & 8,1 \\
Residencial baixa densidade & 0,0 & 35,8 & 5,7 & 3,8 \\
Rodovias & 6,1 & 5,3 & 2,2 & 2,0 \\
Várzeas & 0,7 & 2,6 & 3,7 & 3,1 \\
\hline
\end{tabular}

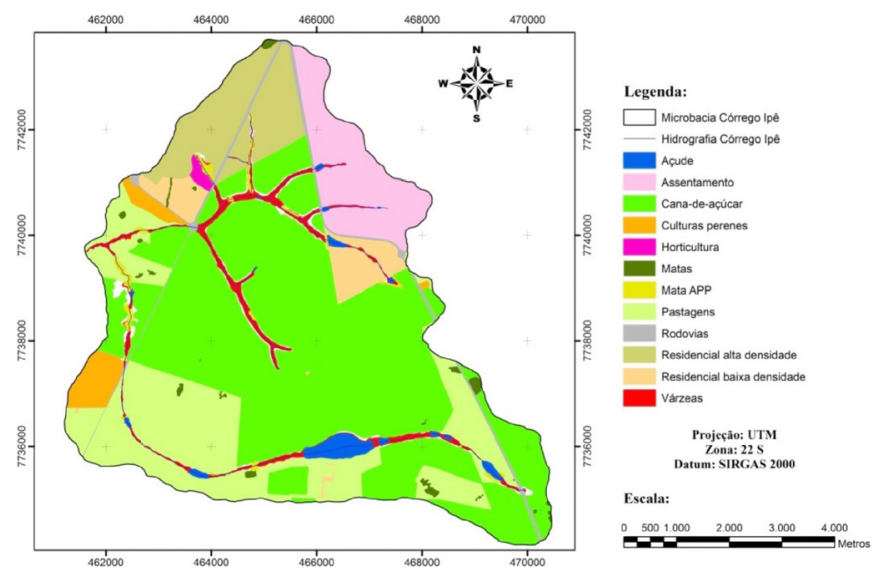

Figura 2. Uso e ocupação do solo na Microbacia do Córrego do Ipê, Ilha Solteira, SP

Em todas as sub-bacias a microbacia apresentou predominância do cultivo da cultura de cana-de-açúcar. A cultura se instalou na região de Ilha Solteira no ano de 2006, ocupando áreas com predomínio de áreas de pastagens. Lima et al. (2004) avaliaram em 43.228 ha de área de pastagem do município de Ilha Solteira, o que representa $66,79 \%$ da área total. Por meio da determinação do uso e da ocupação do solo na microbacia foi possível obter que a área apresentou mudança no uso do solo, apresentando $48,1 \%$ da área compreendida com a cultura da cana-de-açúcar, cultura esta inexistente na região, em anos anteriores.

As últimas décadas foram caracterizadas pelas drásticas mudanças do uso e ocupação do solo na região o que, para Zalidis et al. (2002) representou uma das principais forças motrizes para a degradação ambiental, em especial sobre o solo e a água.

Através das visitas de campo foi possível observar que, ao contrário da cultura de cana-de-açúcar, as áreas de pastagem apresentam má conservação do solo e, além disto, ocorre o pastejo em áreas de preservação permanente. Segundo Barboza (2010) a utilização das técnicas de manejo do solo com destaque para as curvas de nível, seja em áreas de cultivo ou não, reduz a probabilidade de ocorrência de processos erosivos minimizando o assoreamento nos cursos hídricos além de preservar contra prováveis degradações em áreas de preservação permanente.

As áreas de várzeas se caracterizaram com a predominância da espécie herbácea adaptada à saturação hídrica, conhecida como "taboa" (Typha sp.). Planta perene, herbácea, rizomatosa, aquática, com caule cilíndrico e que, devido à sua capacidade de colonização forma um campo úmido antrópico originado por processos de assoreamento de corpos d'água, dando início a um canal indefinido. De acordo com Martins et al. (2007) é muito frequente a ocorrência desta espécie em margens de lagos, canais e várzeas.

As áreas ociosas em conflitos se caracterizaram por áreas próximas às áreas de preservação permanente, que passam por constantes mudanças de uso sendo que a predominância em determinadas épocas do ano é caracterizada por pastagens.

A expansão das áreas urbanas é preocupante visto que acarreta em inúmeros impactos ambientais. $\mathrm{O}$ município de Ilha Solteira aponta, em seu Plano Diretor, a área da microbacia como local estratégico para expansão da área urbana. Para Poleto (2003) a expansão das áreas urbanas próximo a corpos hídricos acarreta em uma das suas principais causas na degradação qualitativa e quantitativa.

Dentre as medidas preventivas Vanzela et al. (2010) destacam que a conservação das áreas de preservação permanente resulta em melhorias qualitativas e quantitativas dos recursos hídricos, favorecendo o planejamento hidroagrícola e ambiental. A determinação das áreas de conflito tem por finalidade determinar se há e quais são as principais influências antrópicas nas áreas de preservação permanente.

A realidade encontrada na Microbacia do Córrego do Ipê é preocupante devido ao uso em conflitos com as APP (Tabela 4) explicado na Figura 3.

No aspecto ambiental a cultura da cana-de-açúcar apresentou melhores condições de manejo do solo e menor interferência nas áreas de preservação permanente, mesmo sinalizando área total 2,4 vezes superior às áreas de pastagem; contudo, a microbacia apresentou 2,1 e 8,3\% das áreas totais de cana-de-açúcar e pastagem, respectivamente, além de uso conflitante com as áreas de preservação permanente. A presença de gado em APP inibe o desenvolvimento de brotos de árvores e a ciclagem de nutrientes e acelera o processo de degradação do solo em virtude da compactação, influenciando diretamente na qualidade dos recursos hídricos. 
Tabela 4. Áreas de conflito do uso do solo com as áreas de preservação permanente na Microbacia do Córrego do Ipê, 2011

\begin{tabular}{lccr}
\hline \multicolumn{1}{c}{ Classes de uso de solo } & Área (ha) & Área $\left.\mathbf{( k m}^{2}\right)$ & \multicolumn{1}{c}{$\%$} \\
Assentamento & 20,25 & 0,20 & 6,5 \\
APP ociosa & 84,73 & 0,85 & 27,0 \\
Cana-de-açúcar & 51,72 & 0,52 & 16,5 \\
Culturas perenes & 1,32 & 0,01 & 0,4 \\
Horticultura & 1,92 & 0,02 & 0,6 \\
Matas & 34,19 & 0,34 & 10,9 \\
Pastagem & 84,49 & 0,85 & 26,9 \\
Residencial alta densidade & 11,56 & 0,12 & 3,7 \\
Residencial baixa densidade & 15,23 & 0,15 & 4,9 \\
Rodovias & 8,24 & 0,08 & 2,6 \\
\hline Área total & 313,65 & 3,14 & 100,0 \\
\hline
\end{tabular}

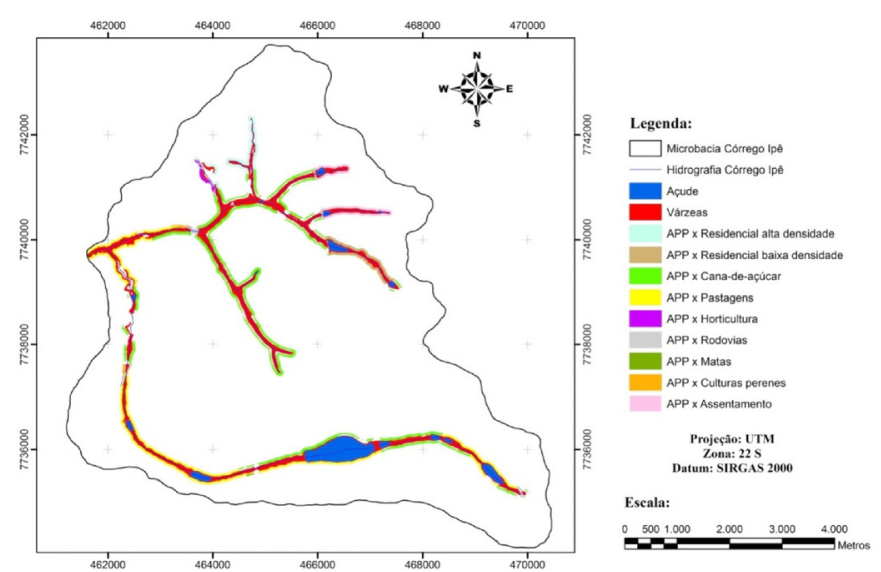

Figura 3. Áreas de conflito com as áreas de preservação permanente na Microbacia do Córrego do Ipê, Ilha Solteira, SP

As áreas de preservação permanente ociosa (APP ociosa) se constituem de áreas de preservação permanente caracterizadas com a predominância da cultura da brachiaria (Urochloa sp.) com algumas árvores isoladas, mesmo que em determinadas épocas do ano a área seja totalmente queimada, o que se deve à concentração de matéria seca sobre o solo, ou seja, área abandonada que proporcionaria melhorias na qualidade e na disponibilidade hídrica, caso fosse reflorestada.

De acordo com Poleto et al. (2010) o mau uso do solo e a ausência de matas ciliares são os principais fatores que favorecem o assoreamento dos mananciais. $\mathrm{O}$ uso inadequado das áreas de preservação permanente pode acarretar impactos ambientais; assim, sua conservação favorece a qualidade das águas servindo como agente regulador de vazão fluvial e, consequentemente, de cheias, na dissipação de energia erosiva das águas de chuvas e pluviais e local de refúgio e fonte de alimentos à fauna.

Para Poleto (2003) apenas 13\% das propriedades agrícolas inseridas na Microbacia do Córrego do Ipê possuem áreas de remanescentes florestais, cada vez menores e raras.

Desta maneira, o conflito na microbacia se encontra bem acentuado com $62,1 \%$ da área de preservação permanente compostos por interferência antrópica. Resultados semelhantes obtiveram Nascimento et al. (2005) ao analisar a Bacia Hidrográfica do Rio Alegre, no município de Alegre, extremo sul do Espírito Santo, que apresentou 78,46\% da interferência antrópica nas áreas preservadas por Lei.
A Tabela 5 apresenta os resultados das análises qualitativas da água do Córrego do Ipê com os valores máximos, mínimos, médios e o erro padrão da média enquanto a Tabela 6 apresenta a correlação entre o uso, a ocupação do solo e os parâmetros da qualidade de água.

A oscilação da temperatura da água influenciou diretamente os mais variados tipos de organismos aquáticos devido à relação existente com o teor de gases dissolvidos (Barboza, 2010). Para Donadio et al. (2005) a oscilação da temperatura está relacionada com a presença e ausência de áreas compostas por mata ciliar; portanto, a temperatura média encontrada no Córrego do Ipê apresentou baixa variação, não apontando riscos ao manancial. A redução do valor da temperatura média ocorrida no ponto de monitoramento 3 está estritamente associada à contribuição do afluente próximo à área urbana evidenciando a ocorrência de lançamento de efluentes; resultados semelhantes foram obtidos por Poleto (2003).

A quantificação dos sólidos e a turbidez demonstraram baixo potencial de danos aos sistemas de irrigação e preocupação em alguns casos isolados (Nakayama \& Bucks, 1986). Observouse que nos períodos de estiagens a concentração de sólidos nos corpos hídricos se eleva moderadamente. Resultados semelhantes foram obtidos por Poleto (2003), Franco \& Hernandez (2009) e Moura et al. (2011). As áreas compostas pela ausência de manejo do solo, escoamento superficial, residencial de alta densidade e loteamento com alta densidade de estradas, favorecem o aumento da concentração de partículas sólidas aos corpos hídricos.

Os valores de $\mathrm{pH}$ apresentaram comportamento médio semelhante nos respectivos pontos de monitoramento. A baixa oscilação do $\mathrm{pH}$ ao longo do tempo pode ser natural sendo que, na maioria dos mananciais, apresentou valores de $\mathrm{pH}$ entre de 6,0 e 8,0; resultados semelhantes também foram obtidos por Poleto (2003) e Basso \& Carvalho (2007); em razão da correlação positiva as áreas de matas, pastagem e culturas perenes, tendem a elevar a alcalinidade da água.

A microbacia caracterizou-se com baixa concentração de íons dissolvidos na água. Para Barboza (2010) os valores de condutividade elétrica estão associados à concentração de sólidos dissolvidos dos mananciais. Esta concentração está estritamente relacionada às características geoquímicas da região, principalmente as áreas degradadas e as áreas com concentração de matéria orgânica e constante adubação.

Os impactos causados pela concentração de ferro total implicam na desuniformidade da aplicação da água pelos emissores e mananciais monitorados por Franco \& Hernandez (2009), Barboza (2010) e Moura et al. (2011) na região noroeste paulista que obtiveram resultados semelhantes. De acordo esses resultados, a origem do ferro total se dá pelas áreas ociosas em conflitos, ocupadas por pastagem e urbanização irregular, áreas de várzeas, loteamento e degradação do solo.

A microbacia apresentou baixa concentração de oxigênio dissolvido em alguns casos isolados. Segundo Barboza (2010) a quantificação do oxigênio dissolvido é um parâmetro de fundamental importância para se manter a vida aquática aeróbica e, não sendo um parâmetro prejudicial aos sistemas de irrigação, sua variação está relacionada a fatores que influenciam na decomposição e atividades metabólicas. 
Tabela 5. Resultados das análises física, química e biológica das Sub-Bacias do Córrego do Ipê no período abril 2006 a setembro 2011

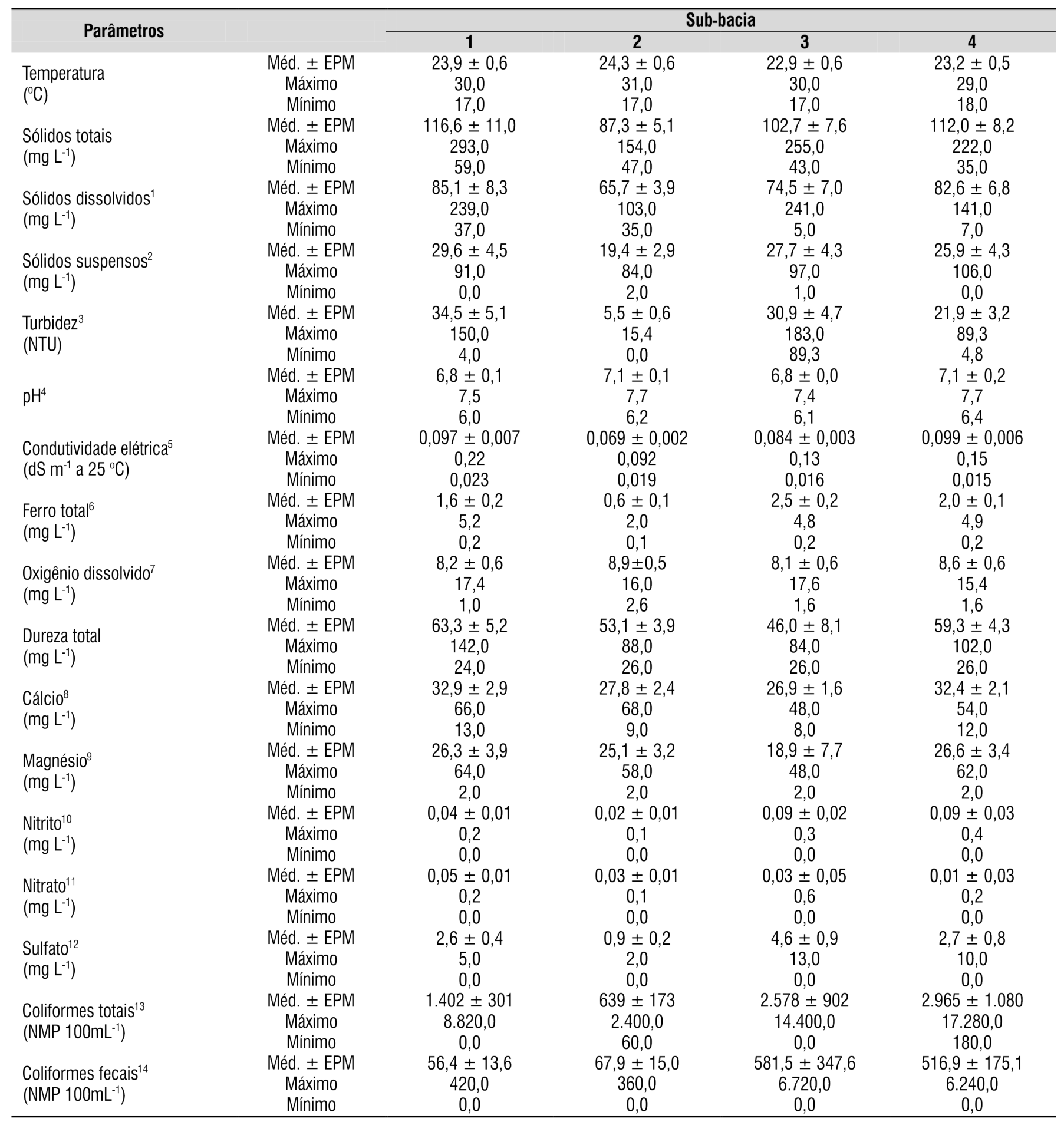

${ }_{1}^{1}$ baixo $\left(<500 \mathrm{mg} \mathrm{L}^{-1}\right)$, médio $\left(500-2000 \mathrm{mg} \mathrm{L}^{-1}\right)$ e alto $\left(>2000 \mathrm{mg} \mathrm{L}^{-1}\right) ;{ }^{2}$ baixo $\left(<50 \mathrm{mg} \mathrm{L}^{-1}\right)$, médio $\left(50-100 \mathrm{mg} \mathrm{L}^{-1}\right)$ e alto $\left(>100 \mathrm{mg} \mathrm{L}^{-1}\right) ;{ }^{3}$ adequado $\left(<100 \mathrm{mg} \mathrm{L}^{-1}\right)$ e inadequado $\left(>100 \mathrm{mg} \mathrm{L}^{-1}\right)$; ${ }^{4}$ baixo $(<7,0)$, médio $(7,0-8,0)$ e alto $(>8,0) ;{ }^{5}$ baixo $\left(<0,250 \mathrm{dScm}^{-1}\right.$ a $\left.25^{\circ} \mathrm{C}\right)$, médio $\left(0,250-0,750 \mathrm{dS} \mathrm{cm}^{-1}\right.$ a $\left.25^{\circ} \mathrm{C}\right)$ e alto $\left(>0,750 \mathrm{dS} \mathrm{cm}^{-1}\right.$ a $\left.25{ }^{\circ} \mathrm{C}\right) ;{ }^{6}$ baixo $\left(<0,2 \mathrm{mg} \mathrm{L}^{-1}\right)$, médio $\left(0,2-1,5 \mathrm{mg} \mathrm{L}^{-1}\right)$ e alto $\left(>1,5 \mathrm{mg} \mathrm{L}^{-1}\right):{ }^{7}$ adequado $\left(\geq 5,0 \mathrm{mg} \mathrm{L}^{-1}\right)$ e inadequado $\left(<5,0 \mathrm{mg} \mathrm{L}^{-1}\right):{ }^{8} \mathrm{normal}\left(\leq 400 \mathrm{mg} \mathrm{L}^{-1}\right)$ e alto $\left(>400 \mathrm{mg} \mathrm{L}^{-1}\right): 9 \mathrm{normal}^{(}\left(\leq 60 \mathrm{mg} \mathrm{L}^{-1}\right)$ e alto $\left(>60 \mathrm{mg} \mathrm{L}^{-1}\right) ; 10 \mathrm{normal}\left(\leq 0,2 \mathrm{mg} \mathrm{L}^{-1}\right)$ e alto

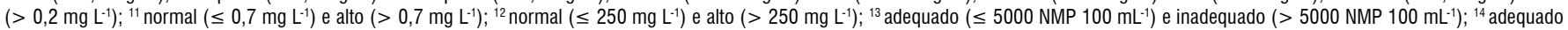
$\left(\leq 1000 \mathrm{NMP} 100 \mathrm{~mL}^{-1}\right)$ e inadequado (> $\left.1000 \mathrm{NMP} 100 \mathrm{~mL}^{-1}\right)$

O uso e a ocupação do solo não apresentaram interferência direta significativa na concentração de oxigênio dissolvido mas se deve dar especial atenção às áreas que influenciam no escoamento de material de origem orgânica; resultados semelhantes foram obtidos por Basso \& Carvalho (2007).

A dureza total (cálcio e magnésio) não apresentou sérios danos quando utilizado o recurso para fins de irrigação.
Segundo Nakayama \& Bucks (1986) a preocupação é quando o pH da água é superior a 7,5 favorecendo, assim, a precipitação do carbonato de cálcio e magnésio resultando na incrustação de tubos e aspersores, o que deixa a microbacia em situação confortável. Resultados semelhantes foram obtidos por Moura et al. (2011). As áreas de pastagem e de constante revolvimento do solo e matas contribuem 
Tabela 6. Correlação do uso e ocupação do solo com a qualidade da água da Microbacia do Córrego do Ipê

\begin{tabular}{|c|c|c|c|c|c|c|c|c|c|c|c|c|c|}
\hline \multirow{2}{*}{$\begin{array}{l}\text { Parâmetros } \\
\text { qualitativos }\end{array}$} & \multicolumn{13}{|c|}{ Uso e ocupação do solo } \\
\hline & CA & PA & AC & VA & MAPP & RO & $\mathrm{CP}$ & AOC & ASS & RBD & RAD & HO & MA \\
\hline STS & $0,19^{*}$ & 0,08 & 0,04 & $-0,15$ & $0,18^{*}$ & 0,04 & 0,14 & 0,06 & 0,00 & $-0,20^{*}$ & $-0,09$ & $-0,09$ & 0,09 \\
\hline SD & 0,16 & 0,10 & 0,02 & $-0,12$ & 0,14 & $-0,01$ & 0,12 & 0,09 & 0,01 & $-0,20^{\star}$ & $-0,09$ & $-0,09$ & 0,09 \\
\hline SS & 0,11 & 0,05 & $-0,06$ & $-0,04$ & 0,08 & $-0,05$ & 0,03 & 0,13 & 0,09 & $-0,19$ & 0,01 & 0,01 & $-0,01$ \\
\hline TD & $0,27^{* *}$ & $-0,02$ & $-0,15^{*}$ & $-0,11$ & $0,22^{\star *}$ & $-0,04$ & 0,02 & $0,24^{* *}$ & $0,32^{* *}$ & $-0,41$ ** & 0,18 & 0,18 & $-0,18$ \\
\hline $\mathrm{pH}$ & $-0,16^{\star}$ & $0,16^{*}$ & 0,20 ** & 0,02 & $-0,12$ & 0,00 & 0,12 & $-0,16^{*}$ & $-0,30 * *$ & 0,15 & $-0,33^{* *}$ & $-0,33^{* *}$ & $0,33^{* *}$ \\
\hline $\mathrm{CE}$ & $0,22^{* *}$ & $0,23^{* *}$ & 0,06 & $-0,17^{\star}$ & $0,18^{*}$ & $-0,06$ & $0,23^{* *}$ & 0,16 & $-0,04$ & $-0,40^{\star *}$ & $-0,26^{\star *}$ & $-0,26^{* \star}$ & $0,26^{*}$ \\
\hline $\mathrm{FE}$ & 0,02 & 0,07 & $-0,46^{\star *}$ & $0,26^{\star \star}$ & $-0,10$ & $-0,46^{\star *}$ & $-0,22^{\star *}$ & $0,60^{\star \star \star}$ & $0,50^{\star *}$ & $-0,65^{\star \star}$ & $0,33^{\star \star}$ & $0,33^{\star *}$ & $-0,33^{\star *}$ \\
\hline $\mathrm{OD}$ & $-0,06$ & 0,04 & 0,04 & 0,03 & $-0,06$ & $-0,02$ & 0,02 & $-0,03$ & $-0,08$ & 0,04 & $-0,08$ & $-0,08$ & 0,08 \\
\hline DT & 0,07 & 0,10 & 0,09 & $-0,10$ & 0,07 & 0,03 & 0,13 & $-0,02$ & $-0,09$ & $-0,04$ & $-0,13$ & $-0,13$ & 0,13 \\
\hline $\mathrm{Ca}$ & 0,14 & 0,15 & $0,16^{*}$ & $-0,18^{*}$ & 0,15 & 0,07 & $0,22^{* *}$ & $-0,04$ & $-0,17$ & $-0,08$ & $-0,30^{* *}$ & $-0,30^{* *}$ & $0,30^{* *}$ \\
\hline $\mathrm{Mg}$ & 0,01 & 0,04 & 0,02 & $-0,02$ & 0,01 & $-0,00$ & 0,03 & 0,00 & $-0,03$ & $-0,02$ & $-0,04$ & $-0,04$ & 0,04 \\
\hline $\mathrm{NO}_{2}$ & $-0,06$ & 0.14 & $-0,16$ & 0,15 & $-0,11$ & $-0.27^{\star}$ & $-0,05$ & 0,28 * & 0,11 & $-0,29 *$ & $-0,01$ & $-0,01$ & 0,01 \\
\hline $\mathrm{Na}$ & $-0,15$ & $-0,01$ & $-0,47^{\star \star}$ & $0,37^{\star * *}$ & $-0,23$ & $-0,45^{\star \star}$ & $-0,33^{* *}$ & $0,51^{\star *}$ & $0,41^{\star *}$ & $-0,41^{\star *}$ & 0,28 & 0,28 & $-0,28$ \\
\hline SU & 0,00 & $-0,01$ & $-0,44^{* *}$ & 0,24 & $-0,09$ & $-0,37^{* *}$ & $-0,25$ & $0,51^{* *}$ & $0,42^{\star *}$ & $-0,42^{* *}$ & 0,29 & 0,29 & $-0,29$ \\
\hline CT & $-0,08$ & 0,15 & $-0,17^{*}$ & $0,17^{\star}$ & $-0,13$ & $-0,29 * *$ & $-0,06$ & $0,29^{* *}$ & 0,11 & $-0,29^{* *}$ & $-0,01$ & $-0,01$ & 0,01 \\
\hline $\mathrm{CF}$ & $-0,13$ & 0,03 & $-0,27^{\star \star}$ & $0,25^{\star \star \star}$ & $-0,18^{\star \star}$ & $-0,30^{\star \star *}$ & $-0,19^{\star}$ & $0,31^{\star \star *}$ & $0,21^{*}$ & $-0,24^{\star \star}$ & 0,12 & 0,12 & $-0,12$ \\
\hline
\end{tabular}

Uso e ocupação do solo: cana-de-açúcar (CA); pastagem (PA); açude (AC); várzea (VA); matas em áreas de preservação permanente (MAPP); rodovias (R0); culturas perenes (CP); áreas ociosas em conflito (AOC); assentamento (ASS); residencial de baixa densidade (RBD); residencial de alta densidade (RAD); horticultura (HO); matas (MA). Parâmetros da qualidade de água: condutividade elétrica - CE (dS m-1 a $\left.25{ }^{\circ} \mathrm{C}\right)$; ferro total - FE (mg L-1); cálcio - Ca (mg L-1); magnésio - Mg (mg L-1); dureza total - DT (mg L-1), sólidos suspensos - SS (mg L-1); sólidos dissolvidos - SD (mg L-1); sólidos totais STS (mg L-1); oxigênio dissolvido - OD (mg L-1); potencial hidrogeniônico- pH; coliformes totais - CT (NMP $100 \mathrm{~mL}^{-1}$ ); coliformes fecais - CF (NMP 100 $\mathrm{mL}^{-1}$ ); turbidez - TD (NTU); nitrato - Na (mg L-1); nitrito - $\mathrm{NO}_{2}\left(\mathrm{mg} \mathrm{L}^{-1}\right)$; sulfato - SU $\left(\mathrm{mg} \mathrm{L}^{-1}\right)$

de forma significativa para o aumento da dureza total nos corpos hídricos.

A determinação do nitrito, nitrato e sulfato, apresentou baixo potencial de degradação dos corpos hídricos. De acordo com Brito et al. (2005) a concentração de nitrato foi elevada em regiões em que o uso intensivo de fertilizantes e defensivos acarreta a eutrofização dos corpos hídricos. Para Gonçalves et al. (2005) concentrações de nitrato acima de $0,2 \mathrm{mg} \mathrm{L}^{-1}$ favorecem na proliferação de plantas aquáticas e, se a água for represada, poder-se-á reduzir o valor de oxigênio dissolvido.

A presença de sulfato nas águas desses mananciais é mínima, mesmo com a abundância deste íon na crosta terrestre.

Em relação à concentração de coliformes totais, todos os pontos de monitoramento, exceto o ponto 2 , apresentaram casos isolados da qualidade da água imprópria para fins de irrigação. Os maiores valores obtidos foram encontrados nos respectivos pontos de monitoramento que recebem influência das áreas urbanas. De acordo com Vanzela et al. (2010) mananciais próximos às áreas habitadas, principalmente moradias rurais, apresentam valores de coliformes totais acima do esperado devido ao lançamento de dejetos e lixos, além da criação de animais.

As determinações de coliformes fecais apresentaram comportamento semelhante ao dos coliformes totais porém a maior concentração deste parâmetro só ocorre nos dois últimos pontos de monitoramento. Além de acarretar sérios danos à saúde pública em virtude do contato direto com a água e/ou contaminação dos alimentos por consumo in natura (Moura et al., 2011), para Barboza (2010) altas concentrações de coliformes podem causar entupimento de emissores, gerando má distribuição hídrica.

Devido à correlação positiva, as concentrações de coliformes estão associadas às áreas ociosas, pastagem, várzeas, assentamento. A correlação não apresentou influência dos residenciais de alta e baixa densidade, porém esses parâmetros foram determinados a partir de monitoramento mais detalhado nos afluentes da microbacia. Poleto et al. (2010) obtiveram resultados semelhantes em afluentes do Córrego do Ipê que recebe influência direta do residencial de alta densidade.

De acordo com Ribeiro et al. (2005) quando houve grandes variações nos parâmetros qualitativos da água de irrigação, estes influenciaram na evolução da perda de carga dos sistemas de filtragem, quando utilizados nos intervalos das retrolavagens.

A presença de açudes favoreceu a redução da velocidade de transporte dos sedimentos e, em contrapartida, na sua decantação, fato observado no segundo ponto de monitoramento em maior parte dos parâmetros analisados. Os demais açudes inseridos no Córrego do Ipê são de estrema importância para crescimento das áreas irrigadas e, em consequência, para o desenvolvimento regional embora tenham apresentado visivelmente, estágio de degradação pela influência nas APP e a má conservação do solo. Os açudes que, embora localizados, em sua maioria, no Córrego das Lagoas, apresentam comportamento inverso ao obtido em toda a extensão do Córrego do Ipê, sendo o entorno com manejo do solo e fragmentos isolados de matas ciliares que não foram identificadas em imagens de satélite.

Para o monitoramento da disponibilidade hídrica tevese como propósito determinar a disponibilidade hídrica da microbacia (Tabela 7) haja vista tratar-se de uma ferramenta que auxilia no planejamento hidroagrícola e ambiental favorecendo o conhecimento da retirada de água ou lançamento de águas residuárias em um manancial.

Em nenhum momento a microbacia apresentou disponibilidade inferior à vazão média plurianual. A variação entre a vazão máxima e a mínima de foi de $87,6,84,7$ e $68,8 \%$ nos pontos de monitoramento 2,3 e 4 . A presença de açudes assoreados é um dos principais fatores de influência diretamente nesta análise, além da ausência de mata ciliar (Vanzela et al., 2010).

A ausência de mata ciliar favorece a degradação dos recursos hídricos aumentando os sedimentos carreados e consequentemente a proliferação de plantas aquáticas como, por exemplo, a taboa (Typha sp.) que é comum nos mananciais da região. De acordo com Oliveira et al. (2011) as matas ciliares podem gerar benefícios diretos e indiretos aos recursos hídricos, além da sua estabilização e permanência. 
Tabela 7. Disponibilidade hídrica na Microbacia do Córrego do Ipê no período de março de 2009 a setembro de 2011

\begin{tabular}{llccc}
\hline \multicolumn{1}{c}{ Disponibilidade hídrica $\left(\mathbf{m}^{\mathbf{3}} \mathbf{h}^{-1}\right)$} & & \multicolumn{3}{c}{ Sub-bacias } \\
\cline { 3 - 5 } & & $\mathbf{2}^{\mathbf{1}}$ & $\mathbf{3}^{\mathbf{1}}$ & $\mathbf{4}^{\mathbf{1}}$ \\
Vazão espećífica & Média \pm EPM & $169,2 \pm 16,5$ & $724,7 \pm 96,6$ & $2.281,7 \pm 241,6$ \\
$\left(\mathrm{~m}^{3} \mathrm{~h}^{-1}\right)$ & Máximo & 482,1 & $2.129,4$ & $3.810,4$ \\
& Mínimo & 59,8 & 325,4 & $1.189,4$ \\
Vazão específica período estiagem ${ }^{2}$ & Média \pm EPM & $146,0 \pm 8,9$ & $604,3 \pm 57,3$ & $2.116,9 \pm 91,1$ \\
$\left(\mathrm{~m}^{3} \mathrm{~h}^{-1}\right)$ & Máximo & 311,1 & $2.104,6$ & $3.810,4$ \\
& Mínimo & 75,1 & 325,4 & $1.189,4$ \\
Vazão específica período chuvoso $^{3}{ }^{3}$ & Média \pm EPM & $211,3 \pm 13,8$ & $941,4 \pm 65,5$ & $2.748,5 \pm 61,5$ \\
$\left(\mathrm{~m}^{3} \mathrm{~h}^{-1}\right)$ & Máximo & 482,1 & $2.129,4$ & $3.332,3$ \\
\hline
\end{tabular}

${ }^{1}$ Valores mínimo, máximo e médio de todas as amostras possíveis determinadas. ${ }^{2}$ Dezembro a março. ${ }^{3}$ Abril a Novembro

Para Martins et al. (2007) o povoamento denso da cultura em açudes e várzeas também provoca desequilíbrio aos corpos hídricos diminuindo ou impedindo seu aproveitamento adequado.

As áreas impermeáveis e a ausência de manejo do solo favorecem a oscilação da vazão de um manancial, uma vez que reduz drasticamente a infiltração e a interceptação favorecendo os picos de vazão (Santos et al., 2009).

De acordo com as características da microbacia, a vazão poderia apresentar melhor disponibilidade caso ocorressem conservação e manejo do solo e das áreas de preservação permanente, a fim de se evitar os picos de vazão, favorecendo a infiltração e a disponibilidade de água na microbacia (Barboza, 2010). Vanzela et al. (2010) explicam que a presença de mata ciliar, além de gerar benefícios qualitativos e quantitativos também favorece o planejamento hidroagrícola e ambiental.

Poleto et al. (2010) avaliaram a mesma área de estudo e constataram indícios de falta de consciência e percepção ambiental dos ribeirinhos os quais negligenciam a utilidade $\mathrm{e}$ a necessidade de se preservar o manancial, sendo que este se torna passível de vir a ser um dos principais fontes de renda local, através da agricultura irrigada.

Fica evidente, portanto, que a má conservação solo e a expansão das áreas urbanas associadas ao uso em conflito com as APP influenciam diretamente na qualidade física e biológica do Córrego do Ipê; desta forma, o monitoramento das águas é de fundamental importância para fins de se constituir um banco de dados e ao mesmo tempo identificar os fatores passíveis de afetar a indisponibilidade hídrica que, sem dúvida, constitui fator limitante para o fortalecimento da agricultura irrigada na região.

\section{Conclusões}

1. A implantação de sistemas de irrigação na Microbacia do Córrego do Ipê sem equipamentos de filtragem acarretará rápida obstrução de tubos e emissores.

2. A microbacia do córrego do Ipê compreende uma área estratégica para a expansão da agricultura irrigada e para o escoamento da produção.

3. As áreas urbanas, a má conservação do solo e as reduzidas áreas de matas, influenciam diretamente na qualidade e na disponibilidade hídrica.

4. O ponto dois de monitoramento (represa) merece atenção especial devido à constatação da sedimentação de sedimentos que se originam à montante.
5. O conhecimento do uso do solo na Microbacia do Córrego do Ipê favorece a identificação de impactos ambientais além do planejamento hidroagrícola e ambiental da área, uma vez que se conhecem todos os fatores que a envolvem.

\section{AgradeCIMENTOS}

Os autores agradecem ao Conselho Nacional de Desenvolvimento Científico e Tecnológico (CNPq) pelo suporte financeiro para a concretização deste trabalho.

\section{LITERATURA CITADA}

Ayers, R. S.; Westcot, D. W. A qualidade da água na agricultura. Campina Grande: UFPB, 1991. 218p.

Barboza, G. C. Monitoramento da qualidade e disponibilidade da água do córrego do Coqueiro no noroeste paulista para fins de irrigação. Ilha Solteira: UNESP, 2010. 143p. Dissertação Mestrado

Barboza, G. C.; Hernandez, F. B. T.; Franco, R. A. M. Análise de riscos à sistemas de irrigação causados pelas qualidade da água do córrego do Coqueiro - SP. Revista Brasileira de Agricultura Irrigada, v.5, p.24-36, 2011.

Basso, E. R.; Carvalho, S. L. Avaliação da qualidade da água em duas represas e uma lagoa no município de Ilha Solteira (SP). Holos Environment, v.7, p.16-29, 2007.

Brasil. Ministério do Meio Ambiente. Conselho Nacional do Meio Ambiente. Resolução N:357, de 17 de março de 2005. <http://www.cetesb.sp.gov.br/Agua/praias/ res_conama_357_05.pdf>. 25 Mai. 2011.

Brito, L. T. de; Srinivassan, V. S.; Silva, A. de S.; Gheyi, H. R.; Galvão, C. de O.; Hermes, L. C. Influência das atividades antrópicas na qualidade das águas da Bacia Hidrográfica do Rio Salitre. Revista Brasileira de Engenharia Agrícola e Ambiental, v.9, p.596-602, 2005.

Donadio, N. M. M.; Galbiatti, J. A.; Paula, R. C. Qualidade da água de nascentes com diferentes usos do solo na Bacia Hidrográfica do Córrego Rico, São Paulo, Brasil. Engenharia Agrícola, v.25, p.115-125, 2005.

Francisco, C. N.; Carvalho, C. N. de. Disponibilidade hídrica - Da visão global às pequenas bacias hidrográficas: $\mathrm{O}$ caso de Angra dos Reis, no Estado do Rio de Janeiro. Revista Geociência, ano 3, p.1-13, 2004. 
Franco, R. A. M.; Hernandez, F. B. T. Qualidade água para fins de irrigação na Microbacia do Córrego do Coqueiro, estado de São Paulo. Revista Brasileira de Engenharia Agrícola e Ambiental, v.13, p.772-780, 2009.

Gonçalves, C. S.; Rheinheimer, D. S.; Pellegrini, J. B. R.; Kirst, S. L. Qualidade da água numa microbacia hidrográfica de cabeceira situada em região produtora de fumo. Revista Brasileira de Engenharia Agrícola e Ambiental, v.9, p.391399, 2005.

Hernandez, F. B. T.; Souza, S. A. V. de; Zocoler, J. L.; Frizzone, J. A. Simulação e efeito de veranicos em culturas desenvolvidas na região de Palmeira d'Oeste, estado de São Paulo. Engenharia Agrícola, v.23, p.21-30, 2003.

Lima, E. A. C. F.; Silva, H. R.; Altimare, A. L. Uso atual da terra no município de Ilha Solteira, SP, Brasil: riscos ambientais associados. Holos Environment, v.4, p.81-96, 2004

Martins, A. P. L.; Reissmann, C. B.; Favaretto, N. F.; Boeger, M. R. T.; Oliveira, E. B. de. Capacidade da Typha dominguensis na fitorremediação de efluentes de tanques de piscicultura na Bacia do Iraí - Paraná. Revista Brasileira de Engenharia Agrícola e Ambiental, v.11, p.324-330, 2007.

Moraes, D. S. de L.; Jordão, B. Q. Degradação de recursos hídricos e seus efeitos sobre a saúde humana. Revista Saúde Pública, v.3, p.370-374. 2002.

Moura, R. da S.; Hernandez, F. B. T.; Leite, M. A.; Franco, R. A. M.; Feitosa, D. G.; Machado, L. F. Qualidade da água para fins de irrigação na Microbacia do Córrego do Cinturão Verde, município de Ilha Solteira. Revista Brasileira de Agricultura Irrigada, v.5, p.68-74, 2011.

Nakayama, F. S.; Bucks, D. A. Trickle irrigation for crop production. St. Joseph: ASAE, 1986. 383p.

Nascimento, M. C. do; Soares, V. P.; Ribeiro, C. A. A. S.; Silva, E. Uso do geoprocessamento na identificação de conflito de uso da terra em áreas de preservação permanente na bacia hidrográfica do Rio Alegre, Espírito Santo. Ciência Florestal, v.15, p.207-220, 2005.

Oliveira, L. C. de; Pereira, R.; Vieira, J. R. G. Análise da degradação ambiental da mata ciliar em um trecho do rio Maxaranguape, RN: Uma contribuição à gestão dos recursos hídricos do Rio Grande do Norte - Brasil. Holos Environment, v.5, p.49-66, 2011.
Paz, V. P. da S.; Teodoro, R. E. F.; Mendonça, F. C. Comunicado técnico: Recursos hídricos, agricultura e meio ambiente. Revista Brasileira de Engenharia Agrícola e Ambiental, v.4, p.465-473, 2000.

Poleto, C. Monitoramento e avaliação da qualidade da água de uma microbacia hidrográfica no município de Ilha Solteira, SP. Ilha Solteira: UNESP, 2003. 161p. Dissertação Mestrado

Poleto, C.; Carvalho, S. L. de; Matsumoto, T. Avaliação da qualidade da água de uma microbacia hidrográfica no município de Ilha Solteira (SP). Holos Environment, v.10, p.95-110, 2010.

Ribeiro, T. A. P.; Airoldi, R. P. da S.; Paterniani, J. E. S.; Silva, M. J. M. Efeitos da qualidade da água na perda de carga em filtros utilizados na irrigação localizada. Revista Brasileira de Engenharia Agrícola e Ambiental, v.9, p.1-6, 2005.

Rolim, G. S.; Camargo, M. B. P.; Lania, D. G.; Moraes, J. F. L. Classificação climática de Köppen e Thornthwaite e sua aplicabilidade na determinação de zonas agroclimáticas de zonas agroclimáticas para o estado de São Paulo. Bragantia, v.66, p.711-720, 2007

Santos, G. O.; Hernandez, F. B. T.; Rossetti, J. C. Balanço hídrico como ferramenta ao planejamento agropecuário para a região de Marinópolis, noroeste do estado de São Paulo. Revista Brasileira de Agricultura Irrigada, v.4, p.142-149, 2010.

Santos, G. O.; Lima, F. B.; Magalhães, F. P.; Brito, C. M. C. M.; Veiga, A. R. Levantamento das condições ambiental dos mananciais inseridos no perímetro urbano do município de Fernandópolis-SP. Universitas, v.5, p.67-84, 2009.

Vanzela, L. S.; Hernandez, F. B. T.; Franco, R. A. M. Influência do uso e ocupação do solo nos recursos hídricos do córrego Três Barras, Marinópolis. Revista Brasileira de Engenharia Agrícola e Ambiental, v.14, p.55-64, 2010.

Young, H. P. Preservação ambiental: Uma retórica no espaço ideológico da manutenção do capital. Revista FAE, v.4, p.25-36, 2001.

Zalidis, G.; Stamatiadis, S.; Takavakoglou, V.; Eskridge, K.; Misopolinos, N. Impacts of agricultural practices on soil and water quality in the Mediterranean region and proposed assessment methodology. Agriculture, Ecosystems and Environment, v.88, p.137-146, 2002. 